\title{
Medullary carcinoma of thyroid gland in a girl aged 10 years
}

\author{
C. E. DENT, J. FACCINI, AND A. HODSMAN \\ From the Metabolic Ward and Department of Oral Pathology, University College Hospital and \\ Dental School, London
}

\begin{abstract}
Dent, C. E., Faccini, J., and Hodsman, A. (1976). Archives of Disease in Childhood, 51, 223. Medullary carcinoma of thyroid gland in a girl aged 10 years. A healthy girl of 10 years presented with lumps on her tongue, shown on biopsy to be neuromas. She had had operations to her feet for pes cavus and was relatively long-limbed but had no other 'Marfanoid' features. She had a high plasma calcitonin level. At operation a normal sized thyroid gland was totally removed. It contained two discrete masses of malignant C-cells and diffuse foci elsewhere. The plasma calcitonin fell slowly to normal on follow-up but was noted to be rising $2 \frac{1}{2}$ years later. We stress the importance of making this diagnosis as early as possible and mention briefly another child aged 15 months, similarly diagnosed and operated upon.
\end{abstract}

Since the original histological description of medullary thyroid carcinoma (Hazard, Hawk, and Crile, 1959) a great deal of interest has been aroused by the multiplicity of the biochemically active compounds it may synthesize. Later it was realized that, in addition to the sporadic form, this tumour also occurred in a familial syndrome associated with multifocal phaeochromocytoma, Cushing's disease, and hyperparathyroidism. This has autosomal dominant expression and is now known as type II multiple endocrine neoplasia (Steiner, Goodman, and Powers, 1968). However, there is a subgroup within this latter syndrome (Gorlin et al., 1968; Cunliffe et al., 1970) who have, in addition, multiple mucosal neuromas. These may be seen on the tongue, eyelids, and lips (which appear thickened). There may also be skeletal abnormalities, including 'Marfanoid' features, pes cavus, and kyphoscoliosis, and intestinal autonomic ganglioneuromatosis with the development of megacolon. Most cases with multiple neuromas have been sporadic and this subgroup may turn out to be a distinct entity. In view of the importance of early diagnosis of such a malignant tumour it is stressed that the mucosal neuromas form an external marker for the potential development of the associated endocrine tumours. We present here a patient in whom the characteristic

Received 23 June 1975. histology of the neuromas led to the diagnosis of a totally asymptomatic medullary thyroid carcinoma, which was later removed.

\section{Case report}

A 7-year-old girl was referred to Professor R. O'Neil of the U.C.H. Dental department in 1970 for surgical removal of an upper labial fraenum, causing a diastema between the upper two incisors. It was noted that she had multiple small nodules in the mucosa of her tongue and the angles of her mouth, apparently present from birth (Fig. 1). When she underwent surgery for re-

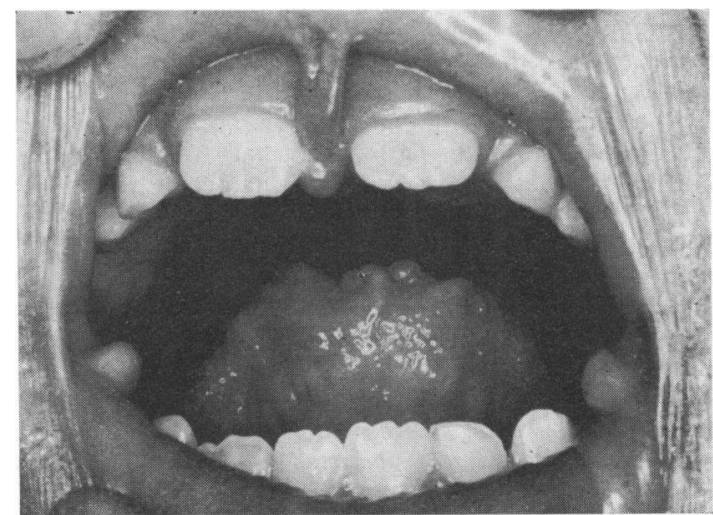

Fig. 1.-Small mucosal nodules on the tip of the tongue and angles of the mouth. 
moval of the fraenum, four of the nodules were biopsied. They each showed a tangled mass of peripheral nerves forming a tumorous mass beneath the mucosa. They were reported as plexiform neuromas by one of us (J.M.F.) (see Fig. 2) but no significance was attached to them until 1973 when a paper was presented at the Oral Pathology Society in Newcastle concerning the association of mucosal neuromata and medullary thyroid carcinoma (Walker, 1973). On the strength of this the child was recalled, and referred to one of us (C.E.D.) for further clinical examination. At this time the girl was well, the thyroid was not enlarged, and there was no cervical adenopathy. She had some 'Marfanoid' features with a high, arched palate and long limbs, while she had had bilateral operations for severe pes cavus in earlier childhood. Her immediate family were alive and well and no relatives were known to have suffered from any endocrine syndromes.

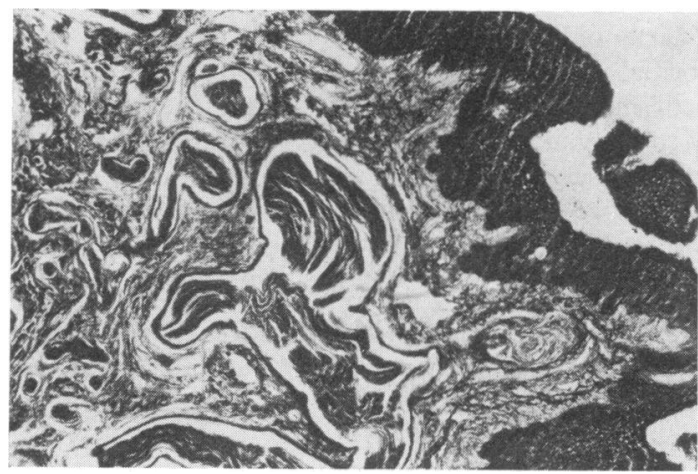

Fig. 2.-Section of mucosal nodule from the tongue showing a tangled mass of peripheral nerves beneath the surface epithelium. (P.T.A.H. $\times 30$.)

Plasma calcium was $9 \cdot 8 \mathrm{mg} / 100 \mathrm{ml}$ (corrected for S. G.); phosphorus $4.8 \mathrm{mg} / 100 \mathrm{ml}$; alkaline phosphatase $21 \mathrm{King}$-Armstrong units $/ 100 \mathrm{ml}$; protein-bound iodine $5.7 \mu \mathrm{g} / 100 \mathrm{ml}$. Bioassay of urine pressor amines was borderline raised at $0 \cdot 15-0 \cdot 20 \mu \mathrm{g} / \mathrm{ml}$ in April 1973, but subsequent estimations have been normal $(<0.10$ $\mu \mathrm{g} / \mathrm{ml}$ ). Calcitonin assays were performed by Professor I. MacIntyre's department. Random plasma calcitonin was raised at $1.26 \mathrm{ng} / \mathrm{ml}$ (normal $<0.50 \mathrm{ng} / \mathrm{ml}$ ). Formal provocation tests were then performed. The oral whisky test (Cohen et al., 1973) was definitely abnormal, showing a rise in plasma calcitonin from 2.07 $\mathrm{ng} / \mathrm{ml}$ fasting, to $3 \cdot 16 \mathrm{ng} / \mathrm{ml}$ at 30 minutes. Similarly, an intravenous infusion of calcium gluconate $(15 \mathrm{mg} / \mathrm{kg}$ over 4 hours) (Coombes et al., 1974) brought a rise from 3.39 to $9 \cdot 14 \mathrm{ng} / \mathrm{ml}$.

On this basis it seemed clear that this girl had an asymptomatic medullary carcinoma of the thyroid and formal exploration was undertaken in April 1973, by Mr. G. L. Bunton who removed totally an apparently normal thyroid gland. However, the cut section of the gland (Fig. 3) showed a circumscribed nodule approximately $1 \mathrm{~cm}$ in diameter in the left lobe and a smaller diffuse area of tumour in the right lobe. Histologically the tumours were typical of medullary thyroid carcinoma (Fig. 4). Furthermore, other parts of the gland showed areas of both C-cell hyperplasia (Fig. 5) and medullary carcinoma, suggesting multifocal sites of tumour formation. It was also of interest that at operation the recurrent laryngeal nerves appeared to be several times their normal diameter.

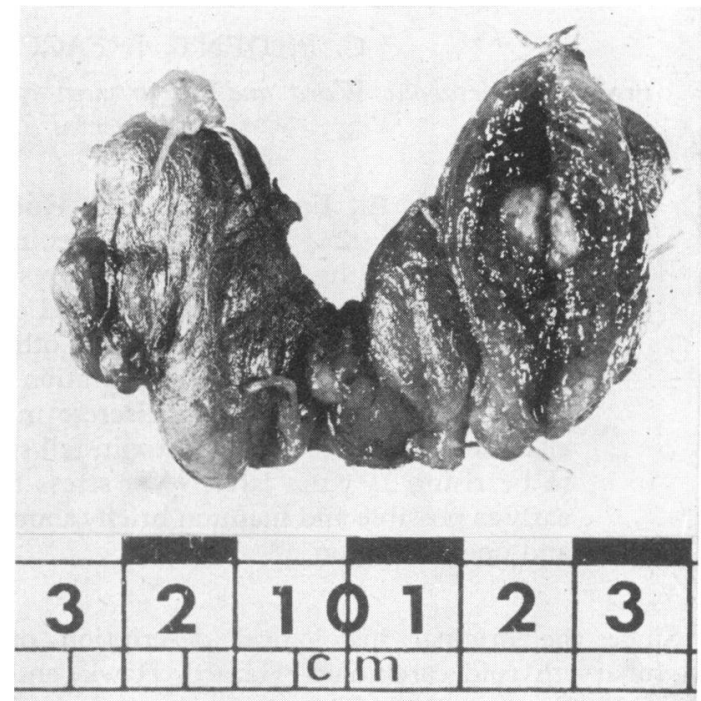

FIG. 3.-The appearance of the thyroid gland after removal. Note the circumscribed tumour in the left lobe and the normal appearance of the right lobe.

Postoperatively she received radiotherapy to the neck, but subsequent recovery was complicated by persistent hypocalcaemia with tetany requiring treatment with dihydrotachysterol (DHT). As of February 1975 she was in good health, with no complaints, and remains on maintenance daily thyroxine $0.2 \mathrm{mg}$ and DHT $0.1 \mathrm{mg}$. There is no clinical evidence of recurrence, but postoperative calcitonin assays gave some cause for concern, being $1 \cdot 76,1 \cdot 20$, and $0 \cdot 29 \mathrm{ng} / \mathrm{ml}$ immediately, at 2 and at 8 months, respectively. Since plasma calcitonin has a half-life of 15 minutes (Cunliffe et al., 1968) the slow decline over several months suggests that residual tumour was left behind at operation, but was being slowly destroyed by scar tissue after irradiation. Unfortunately, high levels of plasma calcitonin have been noted on a recent follow-up (October 1975).

The immediate family (parents and one brother aged $16 \frac{1}{2}$ years) have normal basal plasma calcitonin assays.

\section{Discussion}

Most patients described with medullary carcinoma of the thyroid have presented in adult life as a swelling in the thyroid gland. Others present as a manifestation of other glandular dysfunctions 


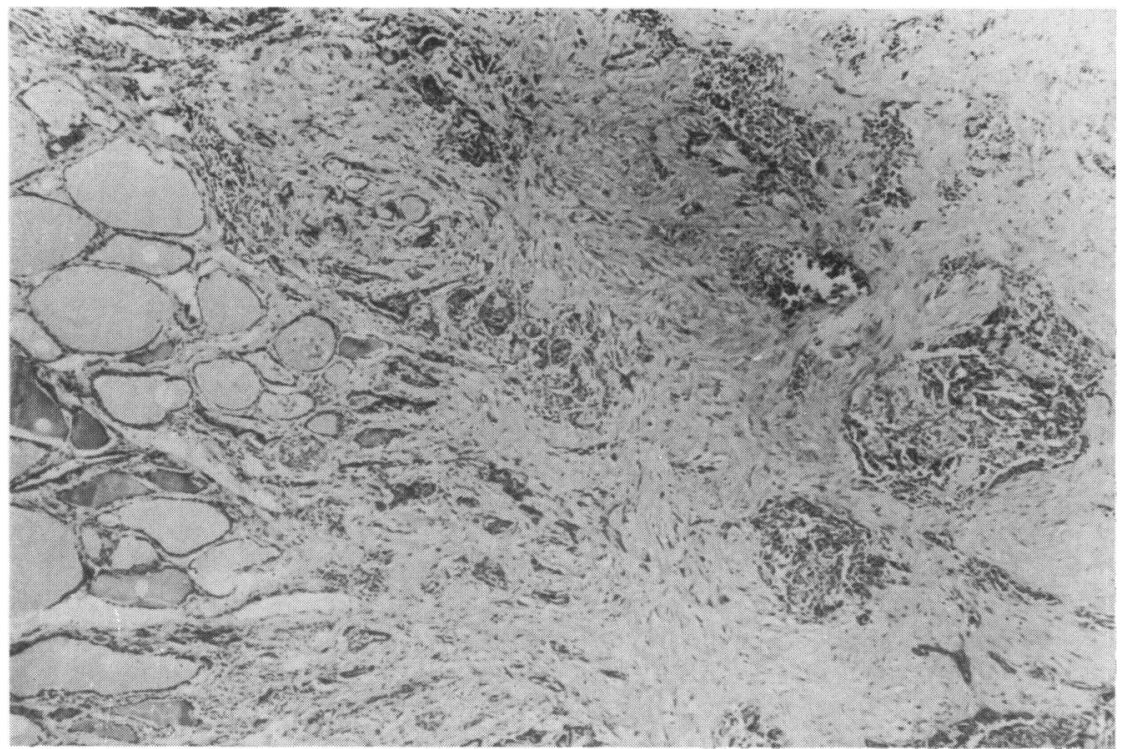

FIG. 4.-An area of medullary carcinoma infiltrating adjacent thyroid follicles on the left. $(H$. and $E . \times 50$.

(parathyroid, adrenal, etc.) and the thyroid carcino$\mathrm{ma}$ is discovered on investigation. We stress the importance of the neuromas and other physical features in our child, since this led to early removal of the tumour which seemed about to spread. The calcitonin assays were the most important investigations leading to the removal of a thyroid gland which was normal on palpation. It must be recalled, however, that a high plasma calcitonin is not specific for this tumour. It has been found

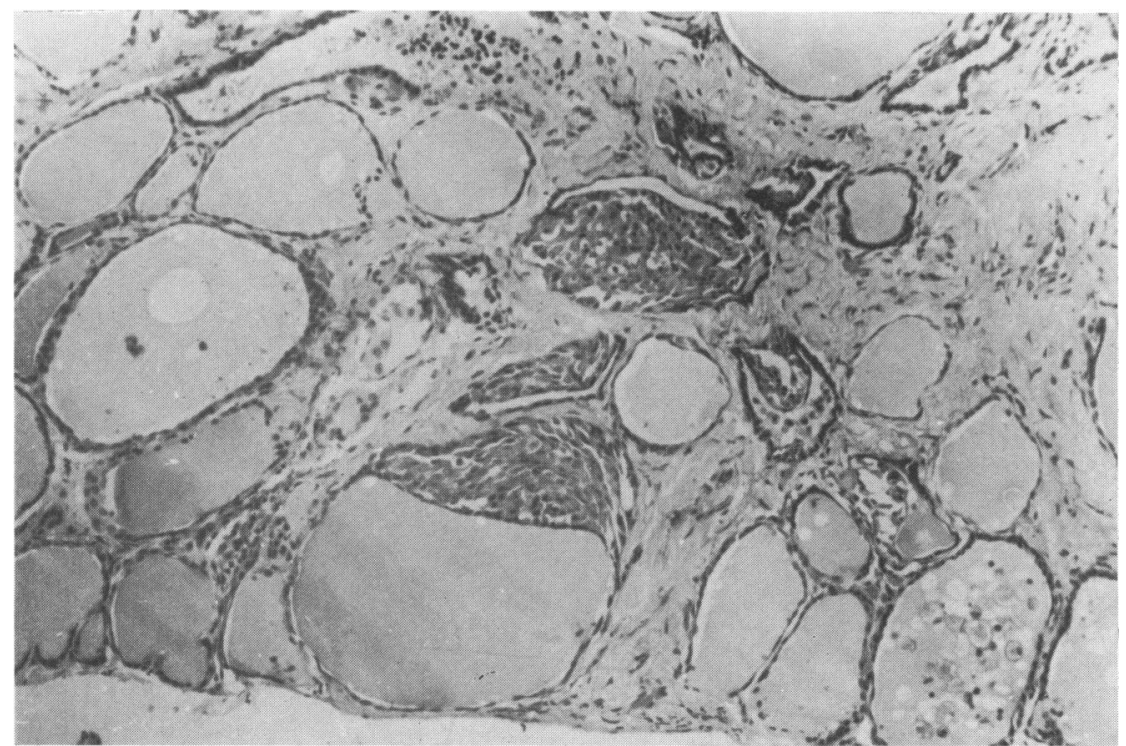

Fig. 5.-A histological section of thyroid taken from an area well away from the tumour in the centre of the lobe. The parafollicular cells form discrete, uniform islands with little cellular atypia. $(H$. and E. $\times 125$. 
to be raised in cancer of very many different organs indeed, in 21 out of a group of 46 patients with cancers of various origins (Coombes et al., 1974), and in a recent publication it seems that calcitonin can also be synthesized by carcinoid tumours (Samaan et al., 1975). It can hardly be envisaged that mass screening programmes for the early detection of thyroid tumours synthesizing calcitonin could become feasible in the near future though the possibility that they could be used as a test for cancer anywhere remains open. We emphasize again, therefore, the value of the physical signs our patient manifested which led to the request for the assay and then to the correct conclusion as to the site of the cancer. Clearly this patient could have been diagnosed much earlier if we had been aware of the problem. Indeed, we have since been referred an even younger patient of only 14 months showing some of these signs. A medullary carcinoma was then removed by Mr. G. L. Bunton. This case will be published later in more detail (F. W. Alexander, personal communication).

We thank Professor I. MacIntyre and Dr. P. B. Greenberg for calcitonin assays and general advice, and Mr. G. L. Bunton for removing the totally asymptomatic normal-sized thyroid gland.

\section{REFERENCES}

Cohen, S. L., MacIntyre, I., Grahame-Smith, D., and Walker, J. G. (1973). Alcohol-stimulated calcitonin release in medullary carcinoma of the thyroid. Lancet, 2, 1172.

Coombes, R. C., Hillyard, C., Greenberg, P. B., and MacIntyre, I. (1974). Plasma-immunoreactive-calcitonin in patients with non-thyroid tumours. Lancet, 1, 1080.

Cunliffe, W. J., Black, M. M., Hall, R., Johnston, I. D. A., Hudgson, P., Shuster, S., Gudmundsson, T. V., Joplin, G. F., Williams, E. D., Woodhouse, N. J. Y., Galante, L., and MacIntyre, I. (1968). A calcitonin-secreting thyroid carcinoma. Lancet, 2, 63.

Cunliffe, W. J., Hudgson, P., Fulthorpe, J. J., Black, M. M., Hall, R., Johnston, I. D. A., and Shuster, S. (1970). Secreting medullary thyroid carcinoma associated with mucosal neuromas, marfanoid features, myopathy and pigmentation. American fournal of Medicine, 48, 120.

Gorlin, R. J., Sedano, H. O., Vickers, R. A., and Cervenka, J. (1968). Multiple mucosal neuromas, pheochromocytoma and medullary carcinoma of the thyroid-a syndrome. Cancer, 22, 293.

Hazard, J. B., Hawk, W. A., and Crile, G. (1959). Medullary (solid) carcinoma of the thyroid-a clinico-pathologic entity. fournal of Clinical Endocrinology, 19, 152.

Samaan, N. A., Hickey, R. C., Bedner, T. D., and Ibañez, M. L. (1975). Hyperparathyroidism and carcinoid tumour. Annals of Internal Medicine, 82, 205.

Steiner, A. L., Goodman, A. D., and Powers, S. R. (1968). Study of a kindred with phaeochromocytoma, medullary thyroid carcinoma, hyperparathyroidism and Cushing's disease: multiple endocrine neoplasia, type 2. Medicine, 47, 371.

Walker, D. M. (1973). Oral mucosal neuroma-medullary thyroid carcinoma syndrome. British fournal of Dermatology, 88, 599.

Correspondence to Prof. C. E. Dent, University College Hospital Medical School, University Street, London WC1E 6JJ. 